\title{
A mulher negra e as relaçōes de poder em Mariana, de Machado de Assis
}

\section{The black woman and the power relations in Mariana, by Machado de Assis}

Andressa dos Santos Vieira ${ }^{1}$

\begin{abstract}
RESUMO
Abordar as relações de poder existentes durante a vigência da instituição da escravidão envolve levantar um misto de questões que enredam a situação do negro que se encontra inserido em um ambiente escravocrata profundamente marcado por um amplo domínio da elite branca em uma sociedade pautada pelas regras do patriarcalismo oitocentista brasileiro. Aproximar-se dessa abordagem através de uma análise aprofundada da situação de Mariana, personagem principal do conto homônimo de Machado de Assis que foi publicado em janeiro de 1871, expõe as diferentes formas como essas relações de poder podem ser causadoras de uma condição de extrema dependência capaz de interferir de maneira significativa na vida tanto da mulher negra e escrava, em situação de privação da liberdade, quanto de seus senhores, permitindo perceber a maneira como o negro vem representado na obra machadiana.
\end{abstract}

PALAVRAS-CHAVE: Machado de Assis; Escravidão; Mulher negra; Relações de poder.

\section{ABSTRACT}

Addressing power relations existing during the term of the institution of slavery involves raising a mix of issues that plot the situation of the negro that is inserted in an slave ambient deeply marked by a broad domination of a white elite that is characteristic of a society based on the rules of brazilian patriarchy in the nineteenth century.Get closer to these approach through in-depth analysis of Mariana's situation, main character of the homonym tale of Machado de Assis that was published in January of 1871, exposes the different ways how these power relation can be the cause of a condition of extreme dependence capable of interfering in a significant way in the life of both the black and slavce woman, in situation of deprivation of liberty, as of her masters, allowing to understand the way the Negro is represented in Machado's work.

KEYWORDS: Machado de Assis; Slavery; Black woman; Power relations.

${ }^{1}$ Mestranda em Letras com pesquisa intitulada O negro em Machado de Assis: escritos da escravidão. Bolsista FAPES. 


\section{Consideraçōes iniciais}

A vastidão da obra de Machado de Assis permite que seus leitores sejam contemplados com a presença de dois contos intitulados Mariana. O primeiro deles foi publicado inicialmente no Jornal das Famílias, em janeiro de 1871 - em setembro do mesmo ano ocorreria a promulgação da Lei do Ventre Livre -, posteriormente incluído na seção Contos Avulsos da Obra Completa da Nova Aguilar; o segundo deles foi publicado inicialmente na Gazeta de Notícias, em outubro de 1891, e incluído no livro de contos Várias Histórias.

A escolha do conto de 1871 para compor este artigo ocorreu devido à estreita relação que ele estabelece com as questões envolvendo as marcas deixadas pela instituição da escravidão, por explorar as relações de poder estabelecidas entre senhores e escravos durante o período escravocrata brasileiro do século XIX, pautado pelo patriarcalismo, e por apresentar diversas possibilidades de pensar como se deu a presença da mulher negra no conto machadiano.

O conto Mariana apresenta como protagonista uma mulher negra e escrava, homônima ao título, que vive na casa de seus senhores e que costuma receber um tratamento diferenciado dos demais escravos da família, pois aprende a ler, escrever, costurar e a falar francês. Certo dia, Coutinho, jovem integrante da família e um dos senhores de Mariana, reencontra Macedo, velho amigo que retorna ao país após viver na Europa durante quinze anos, e reúne-se com ele e mais dois amigos do passado para um almoço. Durante a reunião, Coutinho assume a narração e decide contar aos amigos a história do amor que a jovem escrava nutriu por ele, deixando os mesmos espantados ao revelar que nunca se sentiu tão amado por uma mulher, nem mesmo por sua prima e antiga noiva, como por essa moça tida como uma "cria da casa". 
Coutinho enfatiza que ao apaixonar-se por ele e perceber que tal amor seria impossível de se concretizar, uma vez que o jovem era branco e estava noivo de sua prima Amélia, Mariana, que recentemente havia superado uma grave doença, decide ir embora de casa pela primeira vez, causando irritação na família e fazendo com que o jovem ficasse encarregado de ir atrás dela a fim de levá-la de volta. Pouco tempo depois, ela vai embora de casa mais uma vez, causando um forte sentimento de indignação na família que passa a tê-la como uma ingrata. Novamente o rapaz fica encarregado de procurá-la, mas só consegue encontrar a jovem, que estava escondida em um hotel, dias após seu desaparecimento. Diante da ordem de retorno e consciente de que sua situação de escrava a impossibilitaria de viver o amor que nutria pelo jovem senhor, Mariana decide suicidar-se bebendo um frasco de veneno que levava escondido na roupa e que guardava para o dia do casamento do rapaz.

Percebe-se a força desse conto na singularidade de Machado ao abordar diferentes formas de violência sofridas por escravos, marcas da escravidão brasileira, ao apresentar sua personagem principal na figura de uma jovem mulher negra e escrava que, apesar de viver na casa de seus senhores, saber ler, escrever e supostamente não ser obrigada a realizar trabalhos forçados, acaba por identificar-se com outros negros escravizados por encontrar-se em condição permanente de privação de liberdade e por ser, constantemente, vista e tratada como uma propriedade.

\section{0 papel da mulher negra e as relaçōes de poder na sociedade escravocrata}

Ao ganhar voz na narrativa do amigo Macedo, Coutinho faz uso de seu discurso para caracterizar sua família como extremamente benevolente na apresentação que faz de Mariana: “[...] era uma gentil mulatinha nascida e criada como filha da casa, e recebendo de minha mãe os mesmos afagos que ela dispensava às outras filhas" (MACHADO DE ASSIS, 2015, p. 980). No entanto, acaba 
por deixar transparecer o enorme abismo social estabelecido entre os senhores e escravos quando afirma: "Não se sentava à mesa, nem vinha à sala em ocasião de visitas, eis a diferença; no mais era como se fosse pessoa livre, e até minhas irmãs tinham certa afeição fraternal" (MACHADO DE ASSIS, 2015, p. 980).

Através desse discurso, Coutinho enfatiza que o lugar de Mariana, da mulher negra e escrava, é aquele fora da mesa de jantar e longe das visitas, evidenciando a existência de um enorme distanciamento entre a classe social composta por senhores e aquela composta por negros e escravos. Essa é uma forte característica das relações de poder comumente utilizada pela família do jovem e pela sociedade oitocentista, uma vez que a superioridade do branco sempre necessitou da afirmação de seu poder a partir da negação do sentimento de igualdade ao negro, partindo daí a necessidade do jovem de afirmar que a moça era tratada "como se fosse pessoa livre" e que recebia "certa afeição fraternal", a fim de confirmar sua eterna condição de pessoa "quase livre" e "quase amada", afinal a sensação de plenitude era destinada apenas aos brancos.

Além da privação da liberdade e da negação do sentimento de igualdade, a jovem precisava lidar com a exigência contínua de exprimir sua gratidão aos seus senhores. Esse aspecto fica evidente em outra fala do jovem: "Mariana possuía a inteligência da situação, e não abusava dos cuidados com que era tratada. Compreendia bem que na situação que se achava só Ihe restava pagar com muito reconhecimento a bondade de sua senhora" (MACHADO DE ASSIS, 2015, p. 980). A certeza de não poder abusar tanto da atenção quanto dos cuidados recebidos consiste em evitar punições provenientes da ingratidão, colocando a escrava num lugar subalterno em uma sociedade pautada por uma busca pelo reconhecimento de sua bondade, mas que não hesita em desfrutar da subsistência proporcionada através da exploração do outro.

Sidney Chalhoub (2003, p. 97) afirma que "a ideologia paternalista dos senhores e as relações de dependência provocam situações de violência e humilhação" e despertam em dependentes como Mariana a certeza de que "não há 
perspectivas e que serão sempre lembrados de sua situação de inferioridade social", uma vez que o enredo do conto leva "à imbricação entre escravidão e "liberdade" em situação de dependência, mostrando que havia uma e somente uma lógica hegemônica de reprodução das hierarquias e desigualdades sociais".

Diante desse cenário, é possível afirmar que a ideia de aproximar o escravo da liberdade não se fazia presente numa sociedade predominantemente patriarcal e escravocrata:

A aproximação entre escravidão e liberdade, para enfatizar a precariedade e os limites de qualquer experiência de liberdade numa sociedade paternalista, organizada em torno da reprodução dos laços e dependência pessoal, politiza eficazmente o drama do processo de emancipação dos escravos, então em evidência. Escravidão e paternalismo, cativeiro e dependência pessoal, pareciam duas faces da mesma moeda (CHALHOUB, 2003, p. 98).

A relação de dependência entre senhores e escravos e sua capacidade de provocar situações de violência e humilhação ao dependente ficam evidentes no momento em que "ao mostrar desenvoltura e sentimentos próprios, impróprios na visão dos senhores, Mariana, torna-se [...] presa potencial da rapacidade sexual do senhor moço e até do tio João Luís, pai de Amélia, sempre interessado em colocar aquela 'flor peregrina' sob sua 'proteção'" (CHALHOUB, 2003, p. 97), fato evidenciado na constante indagação do tio ao sobrinho: "Por que diabo está tua mãe guardando aqui em casa esta flor peregrina? A rapariga precisa tomar ar" (MACHADO DE ASSIS, 2015, p. 980).

A cor de sua pele e a posição de inferioridade na sociedade não foram suficientes para impedir que tio e sobrinho a enxergassem como objeto sexual, condição à qual muitas mulheres negras, especialmente as escravas, eram frequentemente submetidas. O interesse sexual do sobrinho fica explícito na afirmação: "[...] entrei a olhar para ela com outros olhos. A rapariga tornara-se interessante para mim, e qualquer que seja a condição de uma mulher, há sempre dentro de nós um fundo de vaidade que se lisonjeia com a afeição que ela nos 
vote. Além disto, surgiu em meu espírito uma ideia que a razão pode condenar, mas que nossos costumes aceitam perfeitamente" (MACHADO DE ASSIS, 2015, p. 984). A partir da afirmação de Coutinho sobre Mariana é possível perceber que "a razão, já impregnada das ideias de liberdade individual, condena que ele se aproprie sexualmente da escrava, embora pelo costume da sociedade brasileira a apropriação sexual representasse tão somente a continuação lógica do cativeiro" (HAPKE, 2010, p. 105).

Outro momento que destaca o interesse que Coutinho nutre pela escrava está exposto na descrição que ele faz da moça, mesmo passados muitos anos entre o fato e o seu resgate memorialístico:

Como tinha inteligência natural, todas estas coisas Ihe foram fáceis. O desenvolvimento do seu espírito não prejudicava o desenvolvimento de seus encantos. Mariana aos dezoito anos era o tipo mais completo de sua raça. Sentia-se-lhe o fogo através da tez morena do rosto, fogo inquieto e vivaz que Ihe rompia dos olhos negros e rasgados. Tinha os cabelos naturalmente encaracolados e curtos. Talhe esbelto e elegante, colo voluptuoso, pé pequeno e mãos de senhora. É impossível que eu esteja a idealizar esta criatura que há tanto me desapareceu dos olhos; mas não estarei muito longe da verdade (MACHADO DE ASSIS, 2015, p. 980).

O fato de Mariana estar sujeita aos abusos proporcionados pelas relações de poder, e imersa nesse ambiente que rechaça todos os direitos aos negros, acaba contribuindo para ela se apaixonar pelo senhorzinho, alcançando o ponto de não conseguir disfarçar sua tristeza diante da confirmação do noivado dele com a prima e fazendo com que Josefa, irmã do rapaz, desconfie que essa profunda tristeza nutrida pela jovem seja fruto de algum namoro. Tal ideia faz com que Coutinho deixe claro, mais uma vez, o lugar da mulher negra e a dimensão da desigualdade social da época ao afirmar que ela só poderia estar envolvida com o copeiro ou o cocheiro por ocuparem posição semelhante e uma vez que "tais sentimentos contrastavam com a fatalidade da sua condição social" (MACHADO DE ASSIS, 2015, p. 983) subalterna e limitadora. 
Diante da impossibilidade de viver seu amor e da proximidade da realização do casamento do rapaz, Mariana decide sair de casa, causando um misto de consternação e indignação em seus senhores que passam a vê-la como uma ingrata, uma vez que:

A ruptura na ordem escravocrata, então, começa no momento em que a escrava deixa de ser apenas um objeto inteiramente dominável. [...] Mariana se constitui como sujeito. Os seus senhores não conseguem apropriar-se inteiramente da personalidade e da alma da jovem cativa. Ao atuar segundo o seu desejo, Mariana não só perturba a ordem escravocrata, mas também inverte os papéis masculinos e femininos da sociedade do século $X I X$, que reservou um lugar passivo para as mulheres (HAPKE, 2010, p. 104).

O posicionamento da família busca afirmar seu poder de dominação, especialmente quando Coutinho sugere que todos os esforços necessários deveriam ser feitos para "capturá-la, e uma vez restituída à casa, colocá-la na situação verdadeira do cativeiro" (MACHADO DE ASSIS, 2015, p. 984), deixando evidente a intenção de restituir, a qualquer custo, a propriedade da família e a necessidade de demonstrar esse poder através dos castigos físicos próprios da situação de cativeiro no retorno da escrava fugida que, a partir de então, não teria mais acesso aos ditos privilégios de outrora.

O rapaz busca ajuda da polícia e mesmo assim não consegue encontrar a escrava desaparecida, o que força seu retorno de mãos vazias. Mais tarde, naquele mesmo dia, ele resolve sair novamente e acidentalmente a encontra na rua e prontamente procura lembrá-la de sua subalternidade: “[...] mas por que saíste de casa, onde eras tão bem tratada, e donde não tinhas o direito de sair, porque és cativa?". A resposta da escrava, de que saiu porque sofria muito, causa indignação no jovem que busca impor sua autoridade: “[...] hás de voltar já, e já, para casa. Sofrerás as consequências da tua ingratidão. Vamos..." (MACHADO DE ASSIS, 2015, p. 985). 
Mesmo diante da pressão exercida por Coutinho, Mariana afirma que não pode voltar devido ao amor que nutre e que não pode ser amada por ser uma "infeliz escrava" pronta para carregar as "consequências" desse amor, deixando claro que tem consciência de seus sentimentos e de sua situação social; desse modo a escrava rompe com a relação de poder estabelecida por seus senhores ao mostrar "desenvoltura e sentimentos próprios" (CHALHOUB, 2003, p. 97), comumente negados aos negros.

Após retornar para casa e ter Coutinho como seu defensor, diante da fúria exprimida pela mãe do rapaz, Mariana vai dormir e no outro dia surge com "os olhos inchados", o que causa certa satisfação no jovem: "a situação da rapariga interessara-me bastante, que era natural, sendo eu a causa indireta daquela dor profunda" (MACHADO DE ASSIS, 2015, p. 986). Passados alguns dias desde seu retorno, Mariana volta a sair de casa, quatro dias antes do casamento do jovem. A notícia foi dada em meio às comemorações do natal, causando um forte sentimento de indignação em toda a família: "este segundo ato de rebeldia da mulatinha produziu furiosa impressão em todos. Da primeira vez houve alguma mágoa e saudade de mistura com a indignação. Desta vez houve indignação apenas" (MACHADO DE ASSIS, 2015, p. 987).

Novamente, Coutinho fica incumbido de ir atrás da escrava, contudo, fica claro que dessa vez ela não escaparia da punição diante do enorme sentimento de indignação que tomou conta da família: "Ficou assentado que se procuraria a fugitiva e se lhe daria o castigo competente. Deixei que esse movimento de cólera se consumasse, e levantei-me para ir procurar Mariana" (MACHADO DE ASSIS, 2015, p. 987). Alguns dias depois, ocasionalmente, ele acaba por encontrá-la em um hotel e a moça rapidamente se lança em seus braços no que o rapaz logo esclarece a situação enquanto busca lembrá-la de sua condição: "Não venho aqui para receber-te abraços [...] venho pela segunda vez buscar-te para casa, donde pela segunda vez fugiste" (MACHADO DE ASSIS, 2015, p. 988). 
Diante do aparente sofrimento que sua fala causa em Mariana, o rapaz busca justificar sua ação, mas acaba deixando transparecer a frieza do homem branco diante da percepção da presença de humanidade no negro:

A palavra fugiste escapou-me dos lábios; todavia, não lhe dei importância senão quando vi a impressão que ela produziu em Mariana. Confesso que deveria ter alguma caridade mais; mas eu queria conciliar os meus sentimentos com os meus deveres, e não fazer com que uma mulher não se esquecesse de que era escrava. Mariana parecia disposta a sofrer tudo dos outros, contanto que obtivesse a minha compaixão. Compaixão tinha-lhe eu; mas não lho manifestava, e era esse todo mal (MACHADO DE ASSIS, 2015, p. 988).

Ao deparar-se com essa dura confirmação de sua situação de cativa, diante do sentimento de propriedade provocado pela palavra "fugiste", Mariana constata que não há outra saída para essa conjuntura que não seja a morte, afinal:

[...] nessas condições, nunca deixaria de ser escrava de uma família, a ponto de anulá-la como ser humano com vontades próprias, tornando-se mais uma vítima sem perspectivas de mudança de sua situação de inferioridade na sociedade. O escravo não estava ali para amar ou demonstrar qualquer sentimento, mas sim a fim de funcionar como uma máquina de trabalho [...] (BIM, 2010, p. 119).

Perante a decisão tomada, Coutinho tenta persuadir Mariana a desistir da fuga para voltar com ele, mas a moça permanece resoluta dizendo estar disposta a tudo, fazendo com que o rapaz suspeite de sua verdadeira intenção e a questione se estaria disposta até mesmo a tirar a própria vida, no que ela finalmente esclarece: "[...] confesso-Ihe até que a minha intenção era morrer na hora do seu casamento, a fim de que fôssemos ambos felizes, nhonhô casando-se, eu morrendo" (MACHADO DE ASSIS, 2015, p. 988). Diante da situação, ele tenta convencê-la a desistir, mas a jovem escrava opta por cometer suicídio ingerindo veneno.

A forma dramática como ocorre a morte de Mariana provoca imensa indignação na mãe do rapaz que só aceita conceder um perdão póstumo após seu 
filho the contar os motivos reais que levaram a moça a esse ato desesperado. Essa revolta diante do suicídio de uma escrava nada mais é do que a certeza de que, "ao tomar a decisão de suicidar-se, ela livra-se da ditadura senhorial e decide por sua vida ou morte, levando ao extremo a morte social que ela sofre numa sociedade que não a quer reconhecer como indivíduo com vontade própria" (HAPKE, 2010, p. 106), pois assim Mariana "personifica a subalternidade feminina e afrodescendente punida de modo trágico a partir do momento em que relação de mando/obediência é afetada pelo desejo ou pela paixão" (DUARTE, 2009, p. 264).

Coutinho encerra sua narração reafirmando aos amigos que nenhuma mulher o havia amado mais do que a jovem escrava Mariana. Seu amigo Macedo retoma a frente da narração ao afirmar que todos ouviram com tristeza as palavras proferidas pelo amigo, mas que logo trataram de sair para se divertir: "[...] daí a pouco saímos pela rua do Ouvidor fora, examinando os pés das damas que desciam dos carros, e fazendo a esse respeito mil reflexões mais ou menos engraçadas e oportunas. Duas horas de conversa tinha-nos restituído a mocidade" (MACHADO DE ASSIS, 2015, p. 989).

Para Eduardo de Assis Duarte (2009, p. 264), Machado de Assis utiliza o "artifício narrativo [...] de dissimular seu posicionamento, dando a palavra ao homem branco, para que ele mesmo se exponha e torne explícita a insensibilidade e o descaso com que trata os afrodescendentes". O que, para ele, viria a se tornar umas das "marcas registradas" do escritor, pois além da ironia presente ao longo desse conto também pode ser identificado o "tom absolutamente sarcástico com que o mesmo se encerra e que revela o distanciamento do autor em relação ao discurso burguês bon vivant encarregado da narração" (p. 264), pois isso se dá através do uso da narrativa em primeira pessoa que "confere ao texto um sentido de relato de experiência" (p. 264), uma vez que representa o posicionamento da classe dominante da época que não hesita em desmerecer o sofrimento da escrava que tira a própria vida por amor ao dar mais importância aos pés de algumas senhoras que descem dos carros na rua. 


\section{Consideraçōes finais}

Fica claro que Machado de Assis trata de maneira singular da temática da escravidão ao longo de Mariana, mesmo sendo um texto pouco conhecido que não chegou a ser selecionado para publicação em livro e que ficou disponível somente em sua publicação no jornal e ao ser incluído na obra completa da Nova Aguilar. A importância desse conto para os estudos sobre a presença do negro na obra machadiana é inegável, pois nele é possível perceber a marca da afrodescendência deixada pelo escritor, uma vez que "nos escritos machadianos não se veem em nenhum momento palavras de apoio, mesmo que implícito ou subentendido, à escravidão. Nem se encontram os estereótipos recorrentes cujo foco é a desumanização dos afrodescendentes" (DUARTE, 2009. p. 252).

Para Chalhoub (2003, p. 98), esse texto carrega consigo, além das marcas de uma sociedade escravista e do ponto de vista machadiano, um valor histórico que o transforma em documento sobre "um impasse histórico, visão ou interpretação de uma crise que mobilizava a sociedade inteira. Ainda que não haja no conto uma identificação precisa do tempo da narrativa, há a postulação de duas historicidades tramadas, constituintes da fala de Coutinho". Isso tudo atrelado ao fato de sua publicação ter ocorrido em janeiro de 1871, durante as discussões sobre a Lei do Ventre Livre, no momento em que a emancipação despontava como principal assunto no país. 


\section{Referências bibliográficas}

BIM, Leda Marana. Amor e morte: uma comparação dos contos "Pai contra mãe" e "Mariana". In: BERNARDO, G.; MICHAEL, J.; SCHÄFFAUER, M. (Orgs.). Machado de Assis e a escravidão. São Paulo: Annablume, 2010. p. 115-124.

CHALHOUB, Sidney. Machado de Assis: historiador. São Paulo, Companhia das Letras, 2003.

DUARTE, Eduardo de Assis. Estratégias de caramujo. In. MACHADO DE ASSIS, J. M. Machado de Assis Afrodescendente: escritos de caramujo [antologia]. Organização, ensaio e notas: Eduardo de Assis Duarte. 2. ed. Rio de Janeiro: Pallas; Belo Horizonte: Crisálida, 2009. p. 249-288.

HAPKE, Ingrid. Tomando liberdades: o escravo "fora do lugar". In: BERNARDD, G.; MICHAEL, J.; SCHÄFFAUER, M. (Orgs.). Machado de Assis e a escravidão. São Paulo: Annablume, 2010. p. 101-114.

MACHADO DE ASSIS, Joaquim Maria. Mariana. In: MACHADO DE ASSIS, Joaquim Maria. Obra completa em quatro volumes. São Paulo: Nova Aguilar, 2015. v. 2, p. 978-990.

Recebido em 14/03/2019

Aceito em 31/07/2019 